\title{
Beschreibung neuer Arten aus der Gattung Caulotrupis WoLLASTON, 1854 (Coleoptera: Curculionidae: Cossoninae) von den Makaronesischen Inseln
}

Mit 62 Figuren und 1 Karte

Peter E. StüBen ${ }^{1}$

${ }^{1}$ Curculio Institut, Hauweg 62, 41066 Mönchengladbach, Germany. - P.Stueben@t-online.de

Published on 2018-08-01

DOI: $10.21248 /$ contrib.entomol.68.1.083-096;

\section{Zusammenfassung}

Acht neue Arten des makaronesischen Genus Caulotrupis Wollaston, 1854 werden beschrieben und in Differentialdiagnosen mit den verwandten Arten verglichen: C. ficvorator spec. nov. (Madeira), C. ficvorator isambertoi ssp. nov. (Deserta Grande), C. portosantoensis spec. nov. (Porto Santo), C. lucifugus faialensis ssp. nov. (north of Madeira), C. xerophilus spec. nov. (Porto Santo \& Ilhéu Chão), C. xerophilus desertagrandensis ssp. nov. (Deserta Grande), C. lourencoensis spec. nov. (Ponta de São Lourenço) und C. wollastoni spec. nov. (Deserta Grande). Eine Karte gibt die Verbreitung der acht neuen Caulotrupis-Arten wieder. Schichtphotos zum Habitus, Aedoeagus und dem weiblichen Genitalapparat werden vorgestellt. Erste molekulare Daten zu den p-Distanzen des mitochondrialen COI-Gens sichern die morphologischen Analysen ab. Es handelt sich um eine vorbereitende Studie zu einer umfassenden Revision des Genus Caulotrupis im Snudebiller.

\section{Taxonomic acts}

Caulotrupis ficvorator spec. nov. - urn:lsid:zoobank.org:act: B9CE3583-6370-45C8-B128-638511C94260'

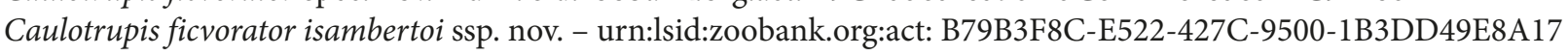

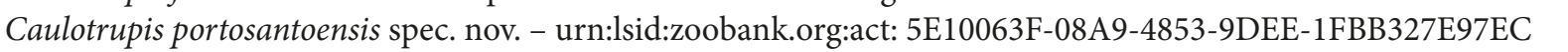

Caulotrupis lucifugus faialensis ssp. nov.

Caulotrupis xerophilus spec. nov. - urn:lsid:zoobank.org:act: $8 \mathrm{EF} 361 \mathrm{E} 2-8 \mathrm{~F} 59-4 \mathrm{BE}-\mathrm{B} 426-\mathrm{B} 2608993 \mathrm{AC} 7 \mathrm{~A}$

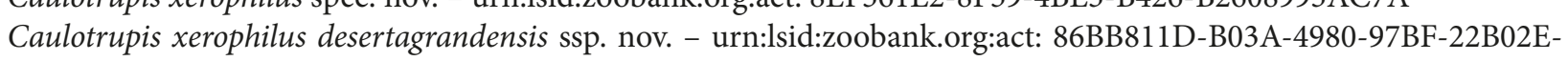
$5 \mathrm{DF} 0 \mathrm{BB}$

Caulotrupis lourencoensis spec. nov. Iurn:lsid:zoobank.org:act: BAFCE97F-5B0F-4109-A71D-D6A8FEA01391'

Caulotrupis wollastoni spec. nov. - iurn:lsid:zoobank.org:act: A093E31C-FD $95-46 \mathrm{~B} 2-9807-7540212 \mathrm{DF} 15 \mathrm{~A}$

\section{Key words}

Coleoptera, Curculionidae, Cossoninae, Caulotrupis, new species, informal groups, morphology, molecular data, distribution maps, Macaronesia, Portugal, Madeira, Porto Santo, Ilhas Desertas, Azores 


\begin{abstract}
Eight new species of the Macaronesian genus Caulotrupis Wollaston, 1854 are described and distinguished from the related species: C. ficvorator spec. nov. (Madeira), C. ficvorator isambertoi ssp. nov. (Deserta Grande), C. portosantoensis spec. nov. (Porto Santo), C. lucifugus faialensis ssp. nov. (north of Madeira), C. xerophilus spec. nov. (Porto Santo, Ilhéu Chão), C. xerophilus desertagrandensis ssp. nov. (Deserta Grande), C. lourencoensis spec. nov. (Ponta de São Lourenço) and C. wollastoni spec. nov. (Deserta Grande). A distribution map with entries and photos (focus stacking) of the habitus, aedeagus and female genitalia of all new taxa are presented. Molecular data on the p-distances of the mitochondrial COI gene support the morphological analyses. It is a preparatory study into a major revision of the genus Caulotrupis in the Snudebiller Journal.
\end{abstract}

\section{Einleitung}

Ein Dutzend Exkursionen führten mich in den letzten 20 Jahren auf das Madeira-Archipel; dazu zählen - neben der Hauptinsel Madeira - Porto Santo im Nordosten und die Ilhas Desertas im Südosten. Außerdem war es mir möglich, in den Jahren 2003 und 2018 die meisten Inseln der Azoren zu bereisen. Dabei fand ich in den vielen Gesieben zu den Cryptorhynchinae, denen mein eigentliches Interesse galt, immer wieder die oft metallisch schillernden, erzglänzenden Exemplare der Caulotrupis-Arten, Cossoninae, die in der überwiegenden Mehrzahl bereits Thomas Vernon Wollaston in seinen zahlreichen Neubeschreibungen zusammengestellt hat (WoLlaston 1854, 1871). Es ist in diesem Zusammenhang beeindruckend, mit welcher Leichtigkeit und Instinktsicherheit er dabei $\alpha, \beta, \gamma \ldots$-Varianten zu den nominotypischen Taxa $z u$ unterscheiden wusste (vgl. MACHADO, 2006), die neben anderen neuen Arten hier erstmals - 160 Jahre danach - als selbständige Arten oder Unterarten beschrieben werden sollen.

Ob man sie nun als Zwillingsarten oder Kryptospezies bezeichnet, ist dabei eher Ansichtssache, denn sie alle sind morphologisch nur sehr schwer, in einigen Fällen nach dem außeren Erscheinungsbild überhaupt nicht zu unterscheiden. Damit werden sie zu einem idealen Gegenstand und Prüfstein für die integrativ-taxonomische Forschung, die molekulare Ergebnisse - wie hier geschehen - zur weiteren Absicherung mit heranzieht. Diese sollen in einer eigenen Revision aller Arten des Genus Caulotrupis im Snudebiller die hier zusammengestellten Erstbeschreibungen begleiten (demnächst in: SтÜвеN \& Schütte 2018). Lectotypenfestlegungen der von Wollaston beschriebenen Arten wurden bereits vom Autor vorgenommen bzw. - weit wichtiger - die entsprechenden Illustrationen (Schichtaufnahmen) der Typusexemplare vorgestellt (STÜBEN 2017b).

Die ungeflügelten Arten des Genus Caulotrupis unterscheiden sich nach B. Folwaczny von allen anderen westpaläarktischen Cossoninae durch 1.5-gliedrige Tarsen, 2. eine völlig glatte Körperoberfläche ohne Schuppen und Borsten, 3. eine fehlende Schulterbeule (Ausnahme: C. chevrolatii Wollaston, 1854), 4. einen längeren als breiteren Rüssel, 5. vorhandene und normal ausgebildete Augen, 6. eine 7-gliedrige Fühlergeißel und 7. eine schwache, oft nur angedeutete Punktur des chagrinierten Pronotums, das etwa bei den PselactusArten viel tiefer und kräftiger punktiert ist. Der Rüssel ist bei den Weibchen länger, bei den Männchen dick und kurz. Die Fühler sind in etwa in der Mitte des Rüssels eingelenkt. Die Punktstreifen sind bei den meisten Arten auf den Elytren kaum erkennbar und können bei ein und derselben Art schwach vorhanden sein oder ganz fehlen. Das Scutellum ist oft nicht erkennbar oder fehlt. Die kahlen Arten zeigen oft einen erzfarbenen, metallischen Glanz (vgl. FolWACZNY 1973).

Die Arten des Genus Caulotrupis sind Endemiten der verschiedenen Inseln des Madeira- (16 Arten) und Azoren-Archipels (1 Art) und kommen vom Meer bis in große Höhen von über 2000 m vor. Sie besiedeln Tothölzer der Laurus-Wälder ebenso wie die abgestorbenen, aber feuchten Stängel strauchartiger Euphorbiaceae des sukkulenten Busches in Meeres- oder Strandnähe. Man findet sie meistens in großer Anzahl unter Weichholzkisten ebenso wie unter faulen Spänen oder Holzklötzen frisch geschnittener Kastanien- oder Laurus-Bäume. Die Arten sind ausgesprochen polyphag. Ihre Verbreitung dürfte vor allem in Stöckchen und dickeren Ästen fluvial und/oder äolisch stattfinden; während die Verbreitung über das offene Meer in Tot- und Treibhölzern - wie bei vielen anderen Cossoninae auch - nichts Ungewöhnliches darstellen dürfte.

\section{Die hochglänzenden neuen Arten der C. impius-Gruppe}

Neben den hier neu beschriebenen drei Arten und Unterarten zähle ich zur C. impius-Gruppe die 5 bekannten Taxa Caulotrupis impius Wollaston, 1854, Caulotrupis chevrolatii WOLLASTON, 1854 und Caulotrupis erberi OsElla \& ZupPA, 1998 (alle vom Madeira-Archipel) und die Art von den Azoren Caulotrupis parvus IsRaElson, 1985. Ich rechne dazu vorerst auch die madeirensische Art Caulotrupis opacus Wollaston, 1854, die molekular in die C. impius-Gruppe fällt, aber aufgrund ihrer umgekehrt eiförmigen Elytren morphologisch viel besser zu den Arten Caulotrupis conicollis Wollaston, 
1854 und Caulotrupis pyricollis Wollaston, 1871 der C. lucifugus-Gruppe passen würde (siehe weiter unten). Zur Systematik der Caulotrupis-Arten siehe auch unsere fast zeitgleich erscheinende Publikation im Snudebiller (STÜвEN \& SCHÜтTE 2018).

\section{Caulotrupis ficvorator spec. nov.

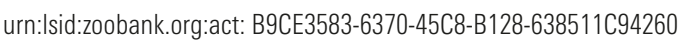 (Fig. 1.1, 2.1, 3.1, 4, 5)}

Holotype: $1 \sigma^{\text {*: }}$ "Madeira, Santa Madalena, Salão, Steilküste, 3251'59"N 17²11'55"W, $320 \mathrm{~m}$, Ficus carica, 8.7.2014, leg. Stüben (34)", coll. SDEI.

Paratypen: 14 Ex.: Angaben wie unter Holotype, coll. SDEI (1 \%), Stüben / 4 Ex.: "Madeira, near Boaventura: Sao Cristovao, 32 $42^{\circ} 35^{\prime \prime N ~ 16 ~} 58^{\prime} 16^{\prime \prime W}, 32$ m, Ficus carica, 3.7.2014, leg. Stüben (22)", coll. Stüben / 4 Ex.: "Madeira, near Boaventura: Sao Cristovao, 3249'32"N $16^{\circ} 58^{\prime} 11^{\prime \prime W}, 61 \mathrm{~m}$, Ficus carica, 20.3. / 25.11.2015, leg. Stüben (4, 11)", coll. Stüben / 1 Ex.: "Madeira: Santa

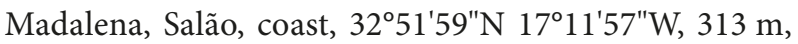
Ficus carica, 4.4.2015, leg. Stüben (22)", coll. Stüben / 1 Ex: "Madeira: Santa Madalena, 30.11.2016, N32 51 '54" W17²12'3", 290 m, sifting under Hedera (on Ficus carica), leg. Stüben (5)", coll. Stüben / 1 Ex.: "Madeira: Seixal, Chão da Ribeira, 30.11.2016, N3248'8" W177'1", 478 m, Laurisilva mit Euphorbia mellifera, leg. Stüben (2)", coll. Stüben / 1 Ex: "Madeira: E Porto da Cruz: Larano (Cova das Pedras), 6.12.2016, N3245'32" W16²7'42", $490 \mathrm{~m}$, coast, sifting, leg. Stüben (14)", coll. Stüben / 2 Ex.: "Madeira: Boaventura, 3.12.2016, N3249'33" W16 58'10", 90 m, sifting under Ficus, leg. Stüben (9)", coll. Stüben / 2 Ex.: "Madeira: N Santana: Quebrada, 20.11.2017, Ficus carica, sifting, 32 $48^{\prime} 49^{\prime \prime} \mathrm{N}, 16^{\circ} 52^{\prime} 27^{\prime \prime W}$, 124 m, 25.11.2015, leg. Stüben (8)", coll. Stüben / 1 Ex.: "Madeira, Arco de S. Jorge W, 300 m, N32 49'33" W165'ㄹ', 19.3.2011, leg. Fritzlar”, coll. Stüben / 3 Ex.: "P-Madeira Isl. Santa Madalena, Pombais 29.3.2017, $32^{\circ} 51^{\prime} 31.8^{\prime \prime} \mathrm{N} 17^{\circ} 12^{\prime} 10.3^{\prime \prime} \mathrm{W}, 400 \mathrm{~m}$, coastal slopes, night beating, Hedera maderensis, lgt. Jan Pelikán, Kopecký", coll. Pelikán, Kopecký / 67 Ex.: "P-Madeira Isl., Salão, Santa Madalena, 16.11.2016 / 26.3.2017, 3251'56.1"N $17^{\circ} 11^{\prime} 57.9^{\prime \prime} \mathrm{W}, 322 \mathrm{~m}$, coastal slopes, night beating, Ficus carica, Hedera, lgt. Jan Pelikán / Krátký / Kopecký", coll. Pelikán, Krátký, Kopecký.

DNA (CO1): 1 Ex: "Madeira: E Porto da Cruz: Larano (Cova das Pedras), 6.12.2016, N3245'32" W16²4'42", $490 \mathrm{~m}$, coast, sifting, leg. Stüben (14), (2917-PST, SDEI)", GenBank: MH013287 / 1 Ex.: "Madeira, Santa Madalena, Salão, Steilküste, 32 $51^{\prime} 59^{\prime \prime N} 17^{\circ} 11^{\prime} 55^{\prime \prime} \mathrm{W}$, 320 m, Ficus carica, 8.7.2014, leg. Stüben (34) (1872PST-26075)", GenBank: MH013275 / 1 Ex.: "Madeira, near Boaventura: São Cristovao, 3249'35"N 1658'16"W, 32 m, Ficus carica, 3.7.2014, leg. Stüben (22) (1889-PST26092)", GenBank: MH013277 / 1 Ex.: "Madeira, Faial, $32^{\circ} 47^{\prime} 37^{\prime \prime N ~ 1650 ' 57 " W, ~} 26$ m, unter Brettern, 20.03.2015, Handfang, leg. P. Stüben (2800-PST-26154)", GenBank:
MH013279 / 1 Ex.: "Madeira, N Machico: Boca do Risco, N3245'19" W1646'19", 348 m, 07.12.2016, sifting, leg. Stüben (2918-PST, SDEI)", GenBank: MH013288.

Beschreibung des nominotypischen Taxons: Länge (ohne Rüssel): 2,2-2,9 mm. Kleinste Art des Madeira -Archipels.

Kopf: Rüssel der Männchen 2,1x länger als breit, parallelseitig bis zur Spitze (ohne eine plötzliche Verbreiterung in Höhe der Fühlereinlenkungen); seitlich dicht bis längsrunzelig punktiert (Punktreihen), oberseitig stark gekrümmt, unterseitig fast gerade im Verlauf; der Rüssel der Weibchen 2,4x länger als breit, ebenfalls parallelseitig, etwas glänzender und feiner, aber im oberen Abschnitt ebenfalls seitlich längsrunzelig punktiert, oberseitig gleichmäßig gebogen, unterseitig nur sehr schwach gekrümmt; Fühler kurz, 1. Fühlerglied dick, 2. Glied deutlich schmaler und etwas länger als breit, die folgenden Glieder zunächst kugelig, die letzten Glieder breitoval, kürzer als breit.

Pronotum: Unwesentlich breiter als lang; oft nicht ganz so hochglänzend wie die Elytren; die nadelstichartige Punktur des chagrinierten, etwas breiteren als langen Pronotums weitläufig: Abstand von zwei- bis dreifachem Punktdurchmesser. Seitenränder nach vorn eher mäßig, zur Basis hin deutlich kräftiger verrundet; breiteste Stelle etwa am Ende des basalen Drittels bzw. zweiten Fünftels.

Elytren: Annähernd zylindrisch, wie das Pronotum erzfarben und hochglänzend, $1,4 \mathrm{x}-1,5 \mathrm{x}$ länger als breit; seitlich gleichmäßig, langoval verrundet (im mittleren Abschnitt am breitesten); Apex breit verrundet; in den meisten Fällen sind schwache, schmale Punktstreifen mit einer feinen, flachen Punktur zu erkennen.

Unterseite: Vorderhüften nur durch eine feine Rinne voneinander getrennt; 1 . Abdominalsegment mit einer feinen, langen, weitläufig platzierten Behaarung (nur bei gerade geschlüpften Exemplaren); 2. Segment etwas länger als das 3 und 4 Segment zusammen.

Aedoeagus: Seitensymmetrischer Aufbau; die Spitze des Aedoeagus jedoch bei ventraler Betrachtung etwas nach links verschoben.

Weibliches Genital: Siehe Fig. 3.1.

Differentialdiagnose: Die hochglänzende, erzfarbene Art ähnelt der Holotype, dem einzigen bisher bekannt gewordenen Exemplar von Caulotrupis erberi OsELLA \& ZuPPA, 1998. Dieses Weibchen, ebenfalls von erzfarbenem Glanz, besitzt jedoch einen stark gekrümmten, deutlich längeren Rüssel sowie eine vollkommen glatte Elytrenoberfläche ohne Punktstreifen. Ein Scutellum ist vorhanden. Der Rüssel der neuen Art ist nur schwach gebogen bzw. annähernd gerade (Fig. 5). Außerdem sind die flachen Punktstreifen auf den Elytren meistens gut zu erkennen. Ein Scutellum ist bei der neuen Art nicht zu erkennen. 
Verbreitung, Ökologie und Etymologie: Die Art lebt im küstennahen Raum auf der Nordseite Madeiras und konnte vom Autor vor allem aus den abgestorbenen Zweigen von Ficus carica herausgebrochen werden. Diesem Fundumstand an der Wirtspflanze Ficus carica wurde bei der Namensgebung Rechnung getragen.

\section{Caulotrupis ficvorator isambertoi ssp. nov.

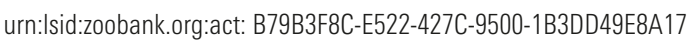 (Fig. 1.2, 2.2, 3.2, 4)}

Holotype: 1 ơ: "Madeira: Deserta Grande (south), above Focinha, 32³0'18"N 16²9'59"W, 215 m, Papaver somniferum somniferum, Crepis divaricata, 24.3.2015, leg. Stüben (8)", coll. SDEI.

Paratypen: 81 Ex.: Angaben wie unter Holotype, coll. SDEI (1 \&), Stüben / 2 Ex.: "Deserta Grande (south), above Furna, 32³0'39"N 16³0'9"W, 247 m, Galactites tomentosa, 24.3.2015, leg. Stüben (7)", coll. Stüben.

DNA (CO1): 1 Ex.: "Deserta Grande (south), above Focinha, 32³0'18"N 16²9'59"W, 215 m, 24.3.2015, leg. Stüben (8) (2803-PST-26157)", GenBank: MH013280.

Beschreibung und Differentialdiagnose: Nicht unerwähnt bleiben darf, dass die zuvor beschriebene, im Norden Madeiras weit verbreitete und nicht seltene Art auf den Ilhas Desertas (Deserta Grande) eine weitere Unterart ausgebildet hat, die sich habituell vom nominotypischen Taxon bis auf den Aedoeagus nicht unterscheidet. Der ebenfalls seitensymmetrisch aufgebaute Aedoeagus zeigt jedoch deutliche Unterschiede: Die aufgebogenen und gegeneinander gerichteten Seiten des Aedoeagus berühren sich, während sie beim nominotypischen Taxon weit voneinander getrennt sind; lateral ist der Aedoeagus stärker gekrümmt. Molekulare Untersuchungen zum mitochondrialen CO1-Gen haben gezeigt, dass die p-Distanzen zwischen beiden Unterarten zwischen 6,8 und 7,6 \% liegen.

Verbreitung, Ökologie und Etymologie: Die hochglänzende, erzfarbene Unterart wurde von Isamberto Silva (Funchal) und dem Autor in Anzahl in den schwach verholzten Stängeln von Galactites tomentosa, Papaver somniferum somniferum und Crepis divaricata auf den südlichen Bergkämmen oberhalb von Focinha der Hauptinsel Deserta Grande im März 2015 gesammelt. Sie kommt dort vergesellschaftet mit C. impius WollaSTON, 1858 vor. Ich widme diese Unterart meinem geschätzten Kollegen Isamberto Silva, "Vigilante da Natureza" im "Parque Natural da Madeira", dessen außergewöhnliche Kenntnisse der Fauna und Flora der Ilhas Desertas mir während meiner Exkursionen eine große Hilfe waren.
Caulotrupis portosantoensis spec. nov.

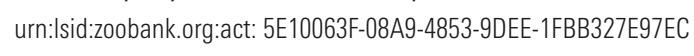
(Fig. 1.3, 2.3, 3.3, 4)

Holotype: 1 ơ: "P: Insel Porto Santo, Pico do Facho, N-Seite $500 \mathrm{~m}$, Laurisilva-Reste (?), 1.IV.1996, leg. Zerche", coll. SDEI.

Paratypen: 6 Ex.: Angaben wie unter Holotype, coll. SDEI, Stüben.

\section{Beschreibung: Länge (ohne Rüssel): 2,5-3,5 mm}

Kopf: Rüssel in beiden Geschlechtern von der Basis bis zur Spitze annähernd parallelseitig (bei den Weibchen zwischen den Fühlereinlenkungen leicht konvex) und sehr fein punktiert; $\sigma^{*} 1,9 x$, ㅇ 2,8x länger als breit. Die hellbraunen Fühler lang und schmal: 1. Fühlergeißelglied dick, 1,3x länger als breit, 2. Glied schmaler, mindestens jedoch $2 x$ länger als breit, 3. und 4 . Glied nur unwesentlich länger als breit, die letzten Glieder eher kugelig.

Pronotum: Glatt, glänzend, chagriniert, 1,13-1,18x breiter als lang, unmittelbar vor der Basis, am Ende des 1. Viertels am breitesten, nach vorn seitlich sehr schwach, nach hinten stark und plötzlich verrundet; Pronotum deutlich, wenn auch fein und sehr weitläufig punktiert; Punktabstände von 2- bis 2,5fachem Punktdurchmesser.

Elytren: Auffallend zylindrisch, metallisch hochglänzend, erzfarben und annähernd parallelseitig; mit feinen, aber stets gut zu erkennenden Punktstreifen; diese neben dem Scutellum deutlich abgesenkt bzw. mit tieferer Punktur; Elytren insgesamt glänzender als das chagrinierte Pronotum; 1,5x länger als breit.

Beine: Rotbraun bzw. dunkelbraun, Tarsen hellbraun. Aedoeagus: Schwach asymmetrisch, mit einer breiten Spitze.

Weibliches Genital: Siehe Fig. 3.3.

Diskussion und Differentialdiagnose: Auch wenn von dieser Art bisher keine molekularen Daten vorliegen, halte ich diese mittelgroße Art vom Pico do Facho für eine eigenständige Art, und das, obwohl Wollaston C. terebrans ebenfalls vom Pico do Facho als die im Vergleich zu C. impius glänzendere Art vorstellt. Trotzdem handelt es sich bei $C$. terebrans nur um eine lokale Variante (mit etwas glatteren und verhältnismäßig glänzenden Elytren) der Art C. impius, die auch auf der Hauptinsel Madeira und den Ilhas Desertas, dem Locus typicus, vorkommt. Wollaston hatte wohl diese Exemplare mit etwas matteren und tiefer gestreiften Elytren im Blick, als er die genannte, im Vergleich glänzendere Variante als eigenständige Art unter dem Namen C. terebrans nochmals beschrieb. Sie kommt mehr oder weniger flächendeckend auf Porto Santo vor und ist dort keineswegs selten. An anderer Stelle habe ich die Synonymisierung auch unter Heranziehung molekularer Studien ausführlich thematisiert (STÜBEN 2017a, 2017b). 
Die hier beschriebene Art muss hingegen in einer verwandtschaftlichen Linie mit den hochglänzenden Arten C.erberi und C. ficvorator von Madeira und Deserta Grande (hier je eine Unterart) gesehen werden. Sie unterscheidet sich jedoch 1 . von C. erberi durch die stets deutlich, wenn auch fein gestreiften Elytren und den deutlich schwächer gekrümmten Rüssel der Weibchen, 2. von C. fivorator ficvorator durch den viel längeren und schmaleren Rüssel der Weibchen ( $+2,8 \mathrm{x}$ vs. 2,4x) und die etwas längeren und annähernd parallelseitigen Elytren und 3. von beiden Unterarten von C. ficvorator durch den stärker asymmetrischen Aufbau und die anders geformte und breiter verrundete Spitze des Aedoeagus. - Tatsächlich ähnelt der Aedoeagus dem der Art C. impius; allerdings ist deren Spitze deutlich breiter verrundet, und vom Habitus her erscheint diese Art, die auf allen Inseln des Madeira-Archipels wohl die häufigste ist, deutlich matter gezeichnet. Die breiteren und seitlich kräftiger verrundeten, breiteren Elytren von C. impius sind niemals hochglänzend (auch wenn man hier die etwas glänzendere Variante dieser Art von Porto Santo berücksichtigt), außerdem viel tiefer gestreift und punktiert.

Verbreitung und Etymologie: Die Art ist bisher nur vom Pico do Facho auf der nordöstlich von Madeira gelegenen kleinen, aber deutlich älteren Insel Porto Santo bekannt.

\section{Die morphologisch schwer zu unterscheidenden neuen Arten der C. lucifugus-Gruppe}

Neben den hier neu beschriebenen fünf Arten zähle ich zur C. lucifugus-Gruppe die vier bekannten Taxa Caulotrupis lucifugus lucifugus Wollaston, 1854, Caulotrupis conicollis Wollaston, 1854, Caulotrupis pyricollis Wollaston, 1871 und Caulotrupis lacertosus Wollaston, 1854. Die folgenden Arten sind morphologisch nicht ganz leicht $\mathrm{zu}$ unterscheiden, daher wird in jedem Fall ein CO1-Barcoding empfohlen (dazu ausführlich meine Revision der Caulotrupis-Arten sowie der Bild-Bestimmungschlüssel im Snudebiller, STÜBEN \& SCHÜtTe 2018).

\section{Caulotrupis lucifugus faialensis ssp. nov.

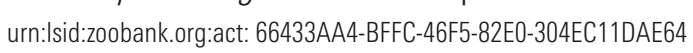 (Fig. 1.4, 2.4. 3.4. 4)}

Holotype: $10^{\top}$ : “Madeira: Faial, 32047'37"N 1650'57"W, $26 \mathrm{~m}$, under wood (Weichholzkisten), 20.3.2015, leg. Stüben (3)", coll. SDEI.

Paratypen: 4 Ex.: Angaben wie unter Holotype, coll. SDEI (1 + ), Stüben / 2 Ex.: "Madeira, 3 km E Santana,

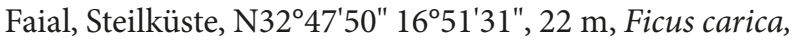

16.3.2008, leg. Stüben (3)", coll. Stüben / 1 Ex.: "Madeira: Faial, 3247'46"N 1651'30", Ficus carica, sifting, 5.7.2014, leg. Stüben (29)", coll. Stüben / 3 Ex.: "Madeira: Santana, 8.12.2016, N32 $48^{\prime} 46^{\prime \prime} \mathrm{W} 16^{\circ} 52^{\prime} 15^{\prime \prime}, 15 \mathrm{~m}$, coast, Ficus, sifting, leg. Stüben (20)", coll. Stüben / 10 Ex.: "Madeira: Achadas da Cruz: Quebrada Nova, sifting, 32 51 '23"N, $17^{\circ} 12^{\prime} 41^{\prime \prime W}, 47 \mathrm{~m}, 04.12 .2015$ / 5.12.2016 / 18.11.2017, coast plateau, leg. Stüben (28)", coll. Stüben / 2 Ex.: "Madeira, W Sao Jorge, Achada da Cruz, 3249'37"N 1653'37"W, 205 m, Laurisilva (rest), Ficus, 14.7.2014, leg. Stüben (44)", coll. Stüben / 17 Ex.: "Madeira: Boaventura, 3.12.2016, N32 $49^{\prime} 33^{\prime \prime} \mathrm{W} 16^{\circ} 58^{\prime} 10^{\prime \prime}, 90 \mathrm{~m}$, sifting under Ficus carica, leg. Stüben (9)", coll. Stüben / 11 Ex.: "Madeira, near Boaventura: Sao Cristovao, 3249'35"N 16 $58^{\prime} 16^{\prime \prime W}, 32 \mathrm{~m}$, Ficus carica, 3.7.2014, leg. Stüben (22)", coll. Stüben / 7 Ex.: "Madeira, 4 km NW Santana: Steilküste São Jorge, N32 $49^{\prime} 59^{\prime \prime}$ W $16^{\circ} 54^{\prime} 00^{\prime \prime}, 35$ m, Tolpis succulenta, 16.3.2008, leg. Stüben (2)", coll. Stüben / 1 Ex.: "Madeira, S Seixal: S Chão da Ribeira, 3247'41.25"N $17^{\circ}$ 6'47.23"W, 509 m, Laurissilva, sifting, 6.7.2014, leg. Stüben (31)", coll. Stüben / 1 Ex.: "Madeira: Sao Vincente: Rota da Cal, sifting, $32^{\circ} 47^{\prime} 51^{\prime \prime N}, 17^{\circ} 01^{\prime} 22^{\prime \prime} \mathrm{W}, 415 \mathrm{~m}$, 30.11.2015, ruderal vegetation, leg. Stüben (18)", coll. Stüben / 1 Ex.: "Madeira: Santa Madalena, 30.11.2016, N32 51'54" W17²1'3", 290 m, sifting under Hedera, leg. Stüben (5)", coll. Stüben / 8 Ex.: "P-Madeira Isl. Santa Madalena, Pombais 29.3.2017, 32 $51^{\circ} 31.8^{\prime \prime} \mathrm{N} \quad 17^{\circ} 12^{\prime}$ $10.3^{\prime \prime} \mathrm{W}, 400 \mathrm{~m}$, coastal slopes, night beating, Hedera maderensis, lgt. Jan Pelikán / Kopecky", coll. Pelikán, Kopecky / 24 Ex.: "P-Madeira Isl., Salão, Santa Madalena, 16./22.11.2016 / 26.3.2017, 3251'56.1"N 17²11'57.9"W, $322 \mathrm{~m}$, coastal slopes, night beating, Ficus carica, Hedera, lgt. Jan Pelikán / Krátký / Kopecký”, coll Pelikán, Kratky, Stüben / 9 Ex.: "Madeira, Pombais pr. Santa Maria Madalena, 32 $51^{\prime} 32.8 \mathrm{~N} 17^{\circ} 12^{\prime} 11.8^{\prime \prime W}, 1.11 .2014$, Ficus carica, leg. Krátký”, coll. Krátký.

DNA (CO1): 1 Ex.: "Madeira, Faial; coast, 3247'37"N 16 $50^{\prime} 57^{\prime \prime} \mathrm{W}, 26 \mathrm{~m}, 04.10 .2014$, sifting, Stüben \& Putzer (3)", (1940-PST-24019), GenBank: MH013278 / 1 Ex.: "Madeira: Ponta Delgada, 29.11.2016, N3249'39" W1659'12", 46 m, Ficus, leg. Stüben (1)", (2906-PST, SDEI), GenBank: MH013285 / 1 Ex.: "Madeira: Santa Madalena, 30.11.2016, N3251'54" W17²1'3", 290 m, sifting under Hedera, leg. Stüben (5)" (2907-PST, SDEI), GenBank: MH013286 / 1 Ex.: "Madeira, W São Jorge, Achada da Cruz, 3249'37"N 1653'37"W, 205 m, Laurisilva (rest), Ficus, 14.7.2014, leg. Stüben (44)" (1882PST-26085), GenBank: MH013276.

Beschreibung: Länge (ohne Rüssel): 2,8-4,2 mm In allen habituellen Merkmalen entspricht diese Unterart der bereits von Wollaston 1854 beschriebenen und bekannten Nominatform vom Cabo Garajau im Süden Madeiras: Caulotrupis lucifugus. Daher soll an dieser Stelle eine Kurzbeschreibung dieser Unterart ausreichen.

Große, lang gestreckte Unterart; Pronotum so lang wie breit, deutlich vor der Basis am Ende des 1. Drittels bzw. 
2. Fünftels am breitesten, nach hinten seitlich stärker, nach vorn flacher verrundet; Pronotumpunktur sehr fein, flach und weitläufig; Rostrum beim Männchen dicht, tief und teilweise kräftig längsrunzelig, beim Weibchen etwas feiner punktiert: ơ 2,0x, ㅇ 2,95x länger als breit; Rostrum bei den Weibchen von den Fühlereinlenkungsstellen bis zur Basis auffallend schmaler werdend, dort stielrund; Rostrum der Männchen bei lateraler Ansicht sehr breit, hakenförmig; Elytren in der Mitte am breitesten und seitlich langoval und gleichmäßig verrundet; Elytren der Männchen in der Regel kürzer (höchstens 1,5x länger als breit), die der Weibchen länger (mindestens 1,6x länger als breit; es gibt Einzelfälle unter den Weibchen, deren Elytren extrem schmal und langoval verrundet sind, $>1,8 \mathrm{x}$ länger als breit); Elytrenpunktstreifen flach, schmal und oft nur angedeutet (bei geringer Vergrößerung zunächst nicht wahrnehmbar), dazwischen auf den Intervallen leicht wellenförmig; Elytren unwesentlich glänzender als das Pronotum, beide jedoch schwarz oder schwarzbraun (mit schwachem erzfarbenem Schein). Basis der Elytren ohne beulenförmig vorgezogene Schulterecken.

Aedoeagus: Bei ventraler Betrachtung annähernd seitensymmetrisch, mit einer deutlich vorgezogenen, langen Spitze.

Differentialdiagnose: Die größte Art des Archipels ähnelt in allen äußeren Merkmalen der Nominatform aus dem Süden Madeiras, bis auf eine Ausnahme: Die Spitze des Aedoeagus ist verlängert bzw. weiter vorgezogen und vom Medianlobus leicht "flaschenhalsartig" separiert; während die der Nominatform kürzer ist und eher spitz-dreieckig ausläuft; außerdem ist der Medianlobus der neuen Unterart bei lateraler Betrachtung deutlich breiter.

Wie die Nominatform ist auch diese Unterart aufgrund ihres auffällig langestreckten Habitus und der langoval verrundeten Elytren mit keiner der kleineren Caulotrupis-Arten auf Madeira zu verwechseln. Die Elytren von C. impius und C. chevrolatii sind eher parallelseitig, die von C. conicollis, C. pyricollis und C. opacus sind umgekehrt eiförmig (oder spindelförmig), und die von C. lacertosus, eine Art, die nur etwas kleiner ist, sind zur Spitze hin viel breiter verrundet und stets tiefschwarz und matt. Molekulare Untersuchungen zum mitochondrialen CO1-Gen haben gezeigt, dass die p-Distanzen zwischen beiden Unterarten zwischen 6,4 und 7,7 \% liegen.

Verbreitung, Ökologie und Etymologie: Die Unterart findet sich im küstennahen Raum zwischen Faial und Porto Moniz bzw. Santa Maria Madalena im regenreicheren Norden von Madeira. Sie kann fast immer aus der Ästchenstreu des etwas feuchteren Detritus der Ficus carica-Anpflanzungen gesiebt werden; sie wurde aber auch vom Autor unter achtlos weggeworfenen Weichholzbrettern und -kisten neben den terrassierten Feldern auf den Steilküsten gesammelt. Nur weil der Feigenbaum ein beliebter Ackerrandbaum mit einem hohen Totholzaufkommen auf Madeira ist, heißt das daher noch nicht, dass diese xylobionte Art nur auf einige wenige Totholz-Wirtspflanzen beschränkt ist. Sie scheint eine ausgesprochen polyphage Art zu sein. Die Steiküsten bei Faial sind ein solch typischer Lebensraum, wo der Autor zum ersten Mal diese neue Unterart nachweisen konnte. Der Ort soll daher namensgebend für die neue Unterart von Caulotrupis lucifugus sein, die in ihrer Nominatform nur im Süden und auf den Ilhas Desertas (dort wahrscheinlich eingeschleppt) vorkommt.

\section{Caulotrupis xerophilus spec. nov.

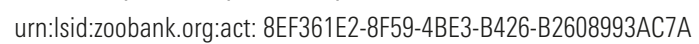 (Fig. 1.5, 2.5, 3.5, 4)}

Holotype: $10^{\star}$ : "Porto Santo East: Pico do Branco (Urze), sifting, $33^{\circ} 05^{\prime} 28^{\prime \prime} \mathrm{N}, \quad 1^{\circ} 18^{\prime} 17^{\prime \prime} \mathrm{W}, 288 \mathrm{~m}, 28.11 .2015$, Cynara cardunculus, leg. Stüben (16)", coll. SDEI.

Paratypen: 11 Ex.: Angaben wie unter Holotype, coll. Stüben / 6 Ex.: "Porto Santo Central: Pico do Castelo, sifting, $33^{\circ} 04^{\prime} 44^{\prime \prime} \mathrm{N}, \quad 16^{\circ} 19^{\prime} 57^{\prime \prime} \mathrm{W}, 273 \mathrm{~m}, 27.11 .2015$, Cynara cardunculus, leg. Stüben (14)", coll. Stüben / 5 Ex.: "Porto Santo Central: Pico do Facho, sifting, $33^{\circ} 04^{\prime} 43^{\prime \prime N}, 16^{\circ} 19^{\prime} 38^{\prime \prime} \mathrm{W}, 251 \mathrm{~m}, 27.11 .2015$, Cynara cardunculus, leg. Schütte (15)", coll. Stüben / 1 Ex.: "Porto Santo West: Cabeco da Ponta, 3302'05"N, 16²1'49"W, $5 \mathrm{~m}, 26.11 .2015$, Crithmum maritimum, coast, leg. Stüben (13)", coll. Stüben / 2 Ex.: "Porto Santo, 2,5 Km N Vila Baleira, Pico Castelo - Pico do Facho, N3304'27" W16 19'25", $146 \mathrm{~m}$, Weide mit Cynara cardunculus, 26.3.2008, leg. Stüben \& Astrin (24)", coll. Stüben / 9 Ex.: "Porto Santo, 3 km N Vila Baleira, Pico Castelo, N3304'51" W16¹9'59", 397 m, Querus ilex \& Q. suber, 26.3.2008, leg. Stüben \& Astrin (23)", coll. Stüben / 4 Ex.: "P. - Porto Santo, Pico Juliana, 400 m, 2.4.(19)93, Wunderle”, coll. Stüben, coll. Behne / 1 Ex.: "Madeira, Porto Santo, Pico Castelo, 250 m, 16.12.1986, leg. Grimm”, coll. Behne / 3 Ex.: "Madeira Archipel, Porto Santo, Pico do Facho, 300-500 m, 16.12.1986, leg. Grimm \& Rachinsky", coll. Behne / 9 Ex.: 'Portugal, Porto Santo, N3304' W16²19', Pico do Facho, 500 m, 1.4.1996, leg. Lompe”, coll. Behne / 1 Ex.: "Portugal, Porto Santo, N33 $05^{\prime} \mathrm{W} 16^{\circ} 18^{\prime}$, Pico Juliano, 450 m, 1.4.1996, leg. Lompe”, coll. Behne / 13 Ex.: "P: Porto Santo, Pico do Castelo, NW-Seite, 400 m, Steineiche, 29.IV.2000, leg. Stüben", coll. Behne.

DNA (CO1): 1 Ex.: "Porto Santo Central: Pico do Castelo, sifting, $33^{\circ} 04^{\prime} 44^{\prime \prime N}, \quad 16^{\circ} 19^{\prime} 57^{\prime \prime} \mathrm{W}, 273 \mathrm{~m}, 27.11 .2015$, Cynara cardunculus, leg. Stüben (14), (2841-PST-4237)", GenBank: MH013284.

Weiteres Material: 8 Ex.: "Ilhéu Chão, near lighthouse (above Furna), 32³5'18"N 16²'39"W, $38 \mathrm{~m}$, Crepis divaricata, Suaeda vera, Sonchus ustulatus, 26.3.2015, leg. Stüben (10)", coll. Stüben. / 2 Ex.: "Ilhéu Chão, Zentrum (Nähe altes Steinhaus), 32³5'7N 16³2'40"W, $61 \mathrm{~m}$, Crepis divaricata, Sonchus ustulatus, 26.3.2015, leg. Stüben (9)", coll. Stüben. 
DNA (CO1): 1 Ex.: "Ilhéu Chão, Zentrum (Nähe altes Steinhaus), $32^{\circ} 35^{\prime} 7 \mathrm{~N} 16^{\circ} 32^{\prime} 40^{\prime \prime} \mathrm{W}, 61 \mathrm{~m}$, Crepis divaricata, Sonchus ustulatus, 26.3.2015, leg. Stüben (9), (2805-PST26159)", GenBank: MH013281.

Beschreibung: Länge (ohne Rüssel): 3,1-4,4 mm.

Kopf: Rüssel in beiden Geschlechtern von der Basis bis zur Spitze parallelseitig und fein punktiert; Fühler rotbraun, zur Keule hin etwas angedunkelt; Fühlerschaft keulenförmig, zur verdickten Spitze hin stark gebogen; 1. Fühlergeißelglied lang und verdickt, 2. Glied schmaler, 1,3x länger als breit, die folgenden Glieder eher kugelig.

Pronotum: Glatt, etwas matter als die glänzenden Elytren; 1,07-1,10x länger als breit, seitlich gleichförmig verrundet, nach vorn etwas schwächer als zur Basis; chagriniert, Punktur äußerst schwach, flach und weitläufig (noch bei mittlerer Vergrößerung kaum zu erkennen).

Elytren: Schmal und sehr lang, in beiden Geschlechtern mindestens 1,5x länger als breit (die Elytren der Weibchen oft noch deutlich länger als die der Männchen), gleichmäßig langoval verrundet, breiteste Stelle etwas vor der Mitte; Oberseite schwarz (wie der ganze Körper bis auf die Beine), glatt, glänzend, ohne Streifen und Punkte (erst bei starker Vergrößerung ist eine extrem feine Punktur zu erkennen); Scutellum nicht vorhanden.

Beine: Rotbraun, Tarsen hellbraun.

Unterseite: Vorderhüften nur durch eine feine Rinne voneinander getrennt; 1. Abdominalsegment nur etwas länger als das 2.; dieses etwa so lang wie die drei folgenden Segmente zusammen.

Aedoeagus: Medianlobus stark zugespitzt; Spitze asymmetrisch, bei ventraler Betrachtung etwas nach rechts verschoben.

Weibliches Genital: Siehe Fig. 3.5.

Differentialdiagnose: Die neue Art von Porto Santo unterscheidet sich von Caulotrupis lucifugus Wollaston, 1854 und ihrer Unterart Caulotrupis lucifugus faialensis durch die deutlich glänzenderen Elytren, die fehlenden Punktstreifen (bei schwacher Vergrößerung), den in beiden Geschlechtern parallelen Rüssel (der bei den Weibchen von C. lucifugus stets zur Basis hin verschmälert und dort stielrund ist) und den zur Spitze hin anderen Verlauf des Aedoeagus. Untersuchungen zum mitochondrialen CO1-Gen haben gezeigt, dass die p-Distanzen zwischen beiden Arten von Madeira (ohne die östliche Halbinsel Ponta de São Lourenço) und Porto Santo zwischen 11,9 und 13,4 \% liegen.

Verbreitung, Ökologie und Etymologie: Diese xerophile Art konnte auf der extrem trockenen Insel Porto Santo stets aus dem Detritus von Cynara cardunculus L. gesiebt werden. Die Fundumstände einer an sehr trockene Verhältnisse angepasste Art standen daher bei der Namensgebung Pate.

Vom akutellen Forschungsstand ausgehend zähle ich zu dieser Art auch die von mir gesammelten und molekular untersuchten Exemplare (CO1, p-Distanz < $3 \%$ ) von der Ilhéu Chão, der nördlichsten und kleinsten Insel der Ilhas Desertas, nicht aber die Exemplare vom Hochplateau der Hauptinsel Deserta Grande, die ich im folgenden als eine weitere Unterart kurz vorstellen möchte.

\section{Caulotrupis xerophilus desertagrandensis ssp. nov.

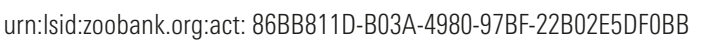 (Fig. 1.6, 2.6, 3.6, 4)}

Holotype: $10^{\text {t': }}$ "Deserta Grande (south), above Focinha, $32^{\circ} 30^{\prime} 18^{\prime \prime} \mathrm{N} 16^{\circ} 29^{\prime} 59^{\prime \prime} \mathrm{W}, 215 \mathrm{~m}$, Papaver somniferum somniferum, Crithmum maritimum, 24.3.2015, leg. Stüben (8)", coll. SDEI.

Paratypen: 4 Ex.: Angaben wie unter Holotype, coll. Stüben / 3 Ex.: "Deserta Grande (north), above Quebrada, $32^{\circ} 33^{\prime} 47^{\prime \prime} \mathrm{N} 16^{\circ} 32^{\prime} 7^{\prime \prime} \mathrm{W}, 204 \mathrm{~m}$, Calendula maderensis, Helminthotheca echioides 30.3.2015, leg. Stüben (14)", coll. Stüben / 13 Ex.: "Deserta Grande (north), Punta Joao Verde, 32³4'14"N 16³2'15"W, 57(-100) m, Galactites tomentosa, Silybum marianum, Calendula maderensis, 30.3.2015, leg. Stüben (15)", coll. SDEI (1 o ), Stüben / 1 Ex.: "Deserta Grande (north), above Faia Grande (Baixio), 32 $31^{\prime} 14^{\prime \prime} \mathrm{N} 16^{\circ} 30^{\prime} 26^{\prime \prime} \mathrm{W}, 251 \mathrm{~m}$, Galactites tomentosa, 29.3.2015, leg. Stüben (12)", coll. Stüben.

DNA (CO1): 1 Ex.: "Deserta Grande (north), above Quebrada, 32³3'47"N 16³2'7"W, 204 m, 30.3.2015, leg. Stüben (14), (2807-PST-26161)", GenBank: MH013282.

Beschreibung und Differentialdiagnose: Länge (ohne Rüssel): 3,2-4,3 mm. Entspricht in allen äußeren Merkmalen dem nominotypischen Taxon von Porto Santo, dazu zählt insbesondere der parallelseitige Rüssel der Weibchen (ein sicheres Unterscheidungsmerkmal zu C. lucifugus von Madeira). Ein Unterschied besteht jedoch in der sehr schwachen Punktur und Streifenbildung der deutlich matteren Elytren, die bereits bei 20-facher Vergrößerung zu erkennen sind (während sie beim nominotypischen Taxon zu fehlen scheinen bzw. erst nach sehr starker Vergrößerung sichtbar werden). Rostrum der Männchen bei lateraler Ansicht deutlich breiter als beim nominotypischen Taxon, hakenförmig. Ein weiteres unverkennbares Differentialmerkmal zum nominotypischen Taxon - und zu allen weiteren Arten und Unterarten aus der C. lucifugus-Gruppe - ist die weit flaschenhalsartig vorgezogene, ebenfalls asymmetrische Spitze des Aedoeagus. Die Unterarten trennen beim mitochondrialen CO1-Gen 5,3-5,6\%.

Verbreitung, Ökologie und Etymologie: Diese zweifellos xerophile Art wurde vom Autor in erster Linie den verholzten Stängeln der Asteraceae Galactites tomentosa (Milchfleckdistel) auf den steil aufragenden Höhenrücken Deserta Grandes, der Hauptinsel der Ilhas Desertas, entnommen. Sie darf nicht verwechselt werden mit C. lucifugus von der Ranger Station "Doca”, die unterhalb der steilen Felswände auf Meeresniveau 
liegt. Letztere Art wurde mit großer Wahrscheinlichkeit zusammen mit Brennholz von der gegenüber liegenden Hauptinsel Madeira (in jüngster Zeit?) eingeschleppt.

\section{Caulotrupis lourencoensis spec. nov.

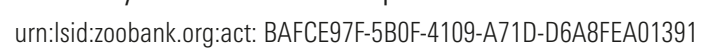 (Fig. 1.7, 2.7, 3.7. 4)}

Holotype: $10^{*}$ : "Madeira: Ponta de São Lourenço, 12.12.2016, N32 $44^{\prime} 51^{\prime \prime} \mathrm{W} 16^{\circ} 42^{\prime} 13^{\prime \prime}, 105$ m, Totholz, leg. Stüben (27)", coll. SDEI.

Paratypen: 2 Ex.: Angaben wie unter Holotype, coll. SDEI (1 + ), Stüben, / 2 Ex.: "Madeira: Ponta de São Lourenço: Pedras Brancas, sifting, $32^{\circ} 44^{\prime} 49^{\prime \prime} \mathrm{N}, 16^{\circ} 42^{\prime} 11.5^{\prime \prime} \mathrm{W}$, 100 m, 23.11.2015, Cynara cardunculus, leg. Stüben (3)”, coll. Stüben / "P. Mad., Ponta de Sao Lourenco, 150 m, $32^{\circ} 44^{\prime} 53^{\prime \prime N} 16^{\circ} 42^{\prime} 07 " \mathrm{~W}, 19.4 .2000$, leg. Stüben”, coll. Stüben; 1 Ex.: "Madeira, Prainha, E of Canical, $118 \mathrm{~m}$, $32^{\circ} 44^{\prime} 57.2^{\prime \prime} \mathrm{N} 16^{\circ} 42^{\prime} 34.9^{\prime \prime W}, 18.11 .2016$, Cynara cardunculus, leg. Krátký, coll. Krátký.

DNA (CO1): je 1 Ex. vom Fundort der Holotype und von Pedras Brancas (Paratype): (2824a-PST-25870, ZFMK), GenBank MH013283, (2920-PST, DEI), GenBank MH013289.

Beschreibung und Differentialdiagnose: Länge (ohne Rüssel): 3,5-4,5 mm.

Die neue Art entspricht in fast allen äußeren Merkmalen der Unterart Caulotrupis xerophilus desertagrandensis: auch bei dieser Art ist eine schwache Punktstreifenbildung auf den Elytren zu erkennen, die - anders als beim nominotypischen Taxon Caulotrupis xerophilus von Porto Santo - eher matt erscheinen. Tiefere Punktrillen zwischen den viel breiteren, etwas aufgewölbten Intervallen sind erst auf dem Elytrenabsturz auszumachen. Auch der Rüssel der Weibchen ist bei dieser Art vor der Basis parallelseitig (anders als bei C. lucifugus, wo er zur Basis hin schmaler wird und hier stielrund ist). Während jedoch der Aedoaegus der Unterart C. xerophilus desertagrandensis von den Höhenzügen der Insel Deserta Grande eine weit vorgezogene, flaschenhalsartige Spitze aufweist, ist diese bei der neuen Art von Ponta de São Lourenço, der östlichen Halbinsel Madeiras, deutlich kürzer. Der Aedoeagus der Unterart Caulotrupis xerophilus xerophilus von der Nachbarinsel Porto Santo ist im Spitzenabschnitt deutlich asymmetrischer.

Sieht man von diesen Unterschieden ab, die eine rein morphologische Zuordnung der Weibchen zur jeweiligen Art fast unmöglich erscheinen lassen, muss man in diesem Fall tatsächlich von einer 'Kryptospezies' sprechen, die sich jedoch molekular erheblich vom Schwestertaxon unterscheidet: so liegen beim mitochondrialen CO1-Gen die p-Distanzen zwischen 8,7 und 9,3\%. Das lässt wenig Raum für die Annahme, dass es sich dabei nicht um zwei reproduktiv isolierte Populationen auf benachbarten Inseln handelt - und dies vor dem Hintergrund, dass die interspezifischen Distanzen bei den übrigen, morphologisch viel besser zu trennenden Caulotrupis-Arten oft noch darunter liegen, während die intraspezifischen Werte bei diesem mitochondrialen Gen selten über $2 \%$ liegen (dazu ausführlich demnächst STÜBEN \& SCHÜtTe 2018).

Verbreitung, Ökologie und Etymologie: Die Art ist bisher nur bekannt von der östlichen, sehr trockenen Halbinsel Madeiras, Ponta de São Lourenço. Dort siebte sie der Autor aus dem Detritus von Cynara cardunculus L. bzw. fand sie unter Totholz.

\section{Caulotrupis wollastoni spec. nov.

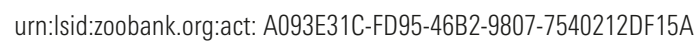 (Fig. 1.8, 2.8, 3.8, 4)}

Holotype: $10^{x}$ : "Deserta Grande, Doca (ranger station), $32^{\circ} 30^{\prime} 49^{\prime \prime} \mathrm{N} 16^{\circ} 30^{\prime} 33^{\prime \prime} \mathrm{W}, 23 \mathrm{~m}$, under wood, 22.3.2015, leg. Stüben (6)", coll. SDEI.

Paratypen: 1 : Angaben wie unter Holotype, coll. Stüben.

Beschreibung: Länge (ohne Rüssel): 2,8-3,0 mm. Kopf: Rüssel in beiden Geschlechtern zur Spitze hin nur wenig breiter werdend. Rostrum: $0^{\star} 1,85 x$, ㅇ 2,40x länger als breit; chraginiert, fein, aber dicht und z.T. längsrunzelig punktiert; Fühler rotbraun, Fühlerschaft keulenförmig, zur verdickten Spitze hin gebogen; 1. Fühlergeißelglied lang und verdickt, 2. Glied schmaler, 1,5x länger als breit, die folgenden Glieder eher kugelig, zur Fühlerkeule hin breiter werdend.

Pronotum: Chraginiert, matt, mit einer sehr feinen, flachen und weitläufigen Punktur; etwa so breit wie lang; breiteste Stelle am Ende des 2. basalen Fünftels; von hier nach vorn sehr schwach, zur Basis hin viel stärker verrundet.

Elytren: Schwarzbraun, umgekehrt eiförmig, 1,4x-1,5x länger als breit; breiteste Stelle vor der Mitte, am Ende des 2. basalen Fünftels (beim Weibchen am Ende des basalen Drittels); wie das Pronotum matt, mit kaum zu erkennenden, sehr feinen, flachen Punktstreifen; Intervalle ebenfalls mit einer sehr schwach ausgebildeten Punktreihe, an keiner Stelle gewölbt; Scutellum nicht zu erkennen.

Beine: Rotbraun bis dunkelbraun, Tarsen heller. Aedoeagus: Symmetrisch; Medianlobus auffallend verrundet, hinter der tellerförmigen Spitze enger werdend, bis zur Basis parallelseitig.

Weibliches Genital: Siehe Fig. 3.8.

Differentialdiagnose: Die auf Deserta Grande verbreitete Art stellt zweifellos die Zwillingsart zu Caulotrupis conicollis Wollaston, 1854 mit ebenfalls umgekehrt eiförmigen Elytren von der Hauptinsel Madeira dar. Sie unterscheidet sich aber von dieser Art durch die matteren Elytren, das eher birnenförmige (also nicht-konische oder trapezförmige Pronotum) und die völlig flachen 
Elytrenintervalle, die bei den Arten C. pyricollis WollasTON, 1871 und C. conicollis auf dem Elytrenabsturz wellenförmig überhöht sind (dort gut zu erkennen auf dem 2., 4. und 6. Intervall). C. opacus Wollaston, 1854 von Madeira mit ebenfalls umgekehrt eifömigen Elytren unterscheidet sich von der neuen Art durch das parallelseitige Pronotum (von der Basis bis zur Mitte des Pronotums) und die abgeflachten Elytren.

Verbreitung, Ökologie und Etymologie: Ich fand die Art in 2 Exemplaren unter Holz in der Nähe der Ranger-Station "Doca” unmittelbar in Meeresnähe auf Deserta Grande. Ebenfalls auf dieser größten Insel der Desertas konnte sie auch Wollaston erstmalig nachweisen und glaubte bereits in dem einzigen Exemplar, das er fand, eine mögliche Variante $\beta$ von Caulotrupis conicollis (Wollaston, 1854: 314) zu sehen. Daher widme ich diese Art dem wohl bedeutendsten Kenner der Käferfauna Makaronesiens: Thomas Vernon Wollaston (1822-1878); siehe auch MaCHADO 2006.

\section{Danksagung}

Mein besonderer Dank gilt Katja Kramp, der Leiterin des Molekularlabors im Senckenberg Deutschen Entomologischen Institut (SDEI, Müncheberg), ebenso wie André Schütte vom Zoologischen Forschungsmuseum Alexander Koenig (Bonn), die beide das von mir gesammelte Material von den Inseln Madeiras molekular aufbereitet haben. Ebenso danke ich den Kollegen Lutz Behne (SDEI, Müncheberg), Jiri Krátký, Jan Pelikán, Thomás Kopecký (alle Tschechische Rep.) und Paulo Borges von der Universidade dos Açores (Terceira) für die Bereitstellung umfangreichen Sammlungs- und Alkoholmaterials sowie Andrea Hastenpflug-Vesmanis vom Senckenberg Forschungsinstitut und Naturmuseum Frankfurt für die Ausleihe der Caulotrupis-Exemplare aus der Sammlung Folwaczny. Umfangreiche Einblicke in die Sammlung von Wollaston mit den von ihm beschriebenen CaulotrupisArten gewährten mir Max Barclay und Roger Booth vom Natural History Museum, London. Für ihre für viele Museen in Europa geradezu vorbildliche Unterstützung wissenschaftlicher Arbeiten (außerhalb ihrer Institution) über zwei Jahrzehnte hinweg möchte ich mich an dieser Stelle herzliche bedanken. Peter Sprick (CURCI, Hannover) gilt mein Dank für das letztmalige Korrekturlesen des Beitrags. Den Behörden auf Madeira danke ich für die Bereitstellung der notwendigen Sammelgenehmigungen. Dies gilt insbesondere für die portugiesische Marine, ohne deren Hilfe meine Forschungsreisen auf die nur schwer zu erreichenden Ilhas Desertas und Ilhas Selvagens unmöglich gewesen wären.

\section{Literatur}

FolwACZNy, B. 1973: Bestimmungstabelle der paläarktischen Cossoninae (Coleoptera, Curculionidae). - Entomologische Blätter, Krefeld 69 (2): 65-180.

Machado, A. M. 2006: T. Vernon Wollaston (18221878). - Un entomólogo en la Macaronesia, Lanzarote: 170 pp.

Osella, G. \& Zuppa, A. M. 1998: New and remarkable Curculionoidea from Macaronesia (Coleoptera). Bocagiana Museu Municipal do Funchal (História Natural) 191: 1-12.

StüBEn, P. E. 2017a: Die Curculionoidea (Coleoptera) von den Inseln Madeiras und den Selvagens. Snudebiller: Studies on taxonomy, biology and ecology of Curculionoidea 18 (261): 1-92, CURCULIOInstitute: Mönchengladbach.

STÜBEN, P. E. 2017b: New nomenclatural and taxonomic acts, and Comments (2016/2017). - Snudebiller: Studies on taxonomy, biology and ecology of Curculionoidea 18 (265): 1-16, CURCULIO-Institute: Mönchengladbach.

StüBEN, P. E. 2018: Revision der Caulotrupis-Arten von den Makaronesischen Inseln (Coleoptera: Curculionidae: Cossoninae). - Snudebiller: Studies on taxonomy, biology and ecology of Curculionoidea 19: (in press), CURCULIO-Institute: Mönchengladbach.

Wollaston, T. V. 1854: Insecta Maderensia; being an account of the insects inhabiting the islands of the Madeiran group. _- London: J. van Voorst, xliii _. 634 pp., 13 pls. - https://Www.biodiversitylibrary.org/1 item $/ 37267 \#$ page/7/mode/liup.

Wollaston, T. V. $1 \overline{8} \overline{1}$ : Ōn additions to the Atlantic Coleoptera. - Transactions of the Entomological Society of London 1871:_203-314. - "https://www.' biodiversitylibrary.org/item/51221\#page $/ 225 \overline{7}_{1}$ imode/lupi 


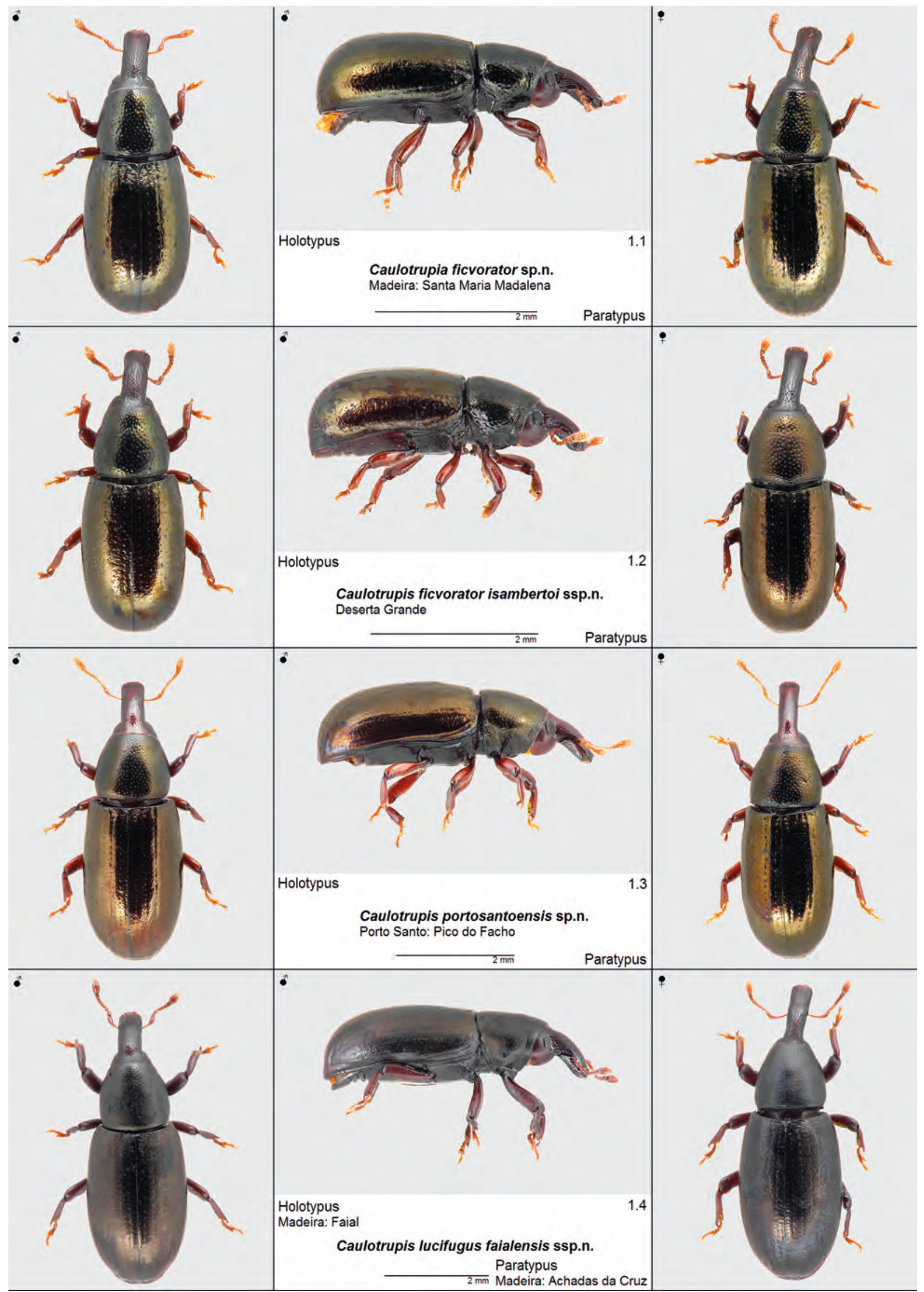

Fig. 1.1-1.4: Die neuen Caulotrupis-Arten. Habitus ơ (dorsal / lateral); Habitus ㅇ (dorsal). 


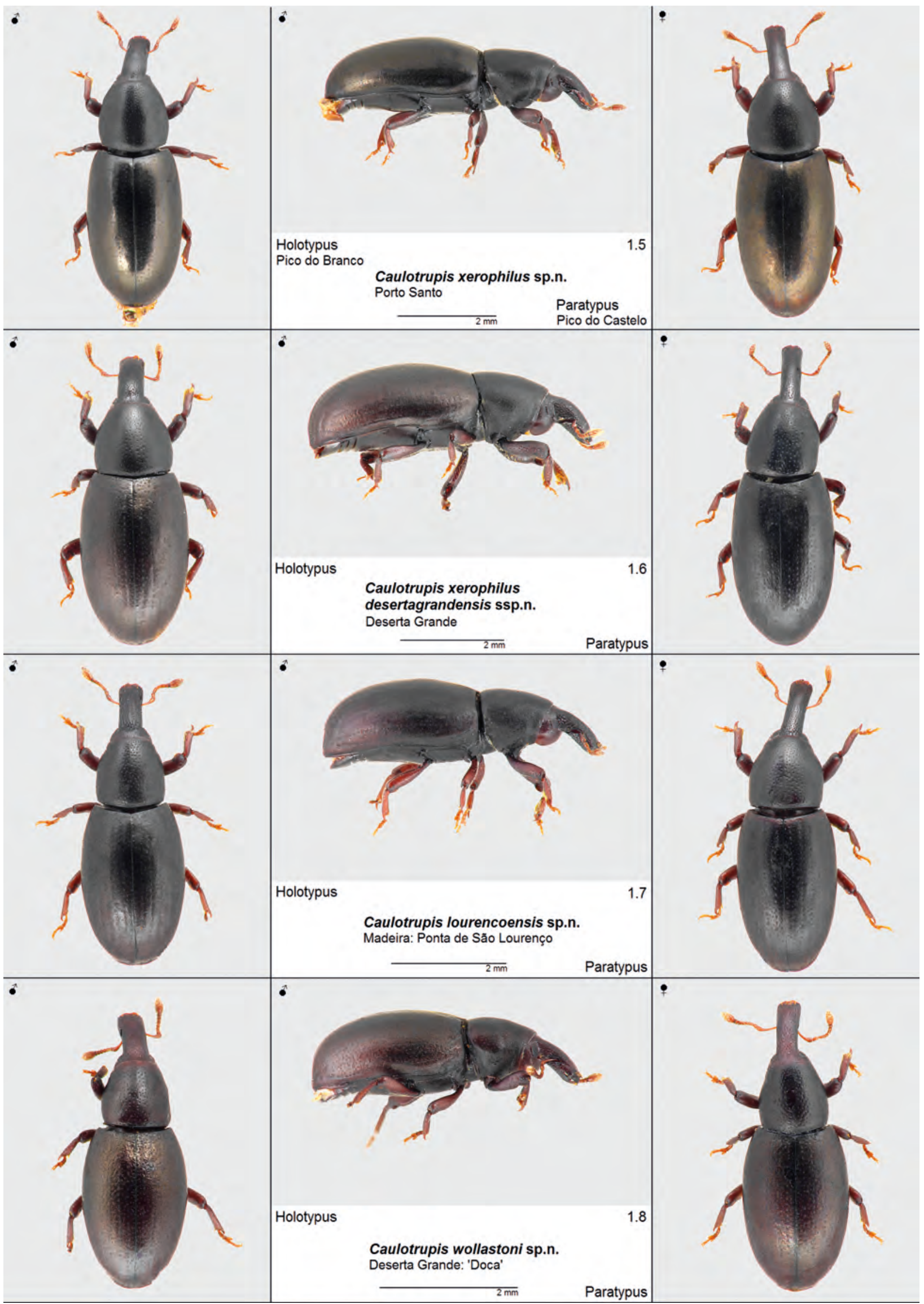

Fig. 1.5-1.8: Die neuen Caulotrupis-Arten. Habitus ơ (dorsal / lateral); Habitus ㅇ (dorsal). 


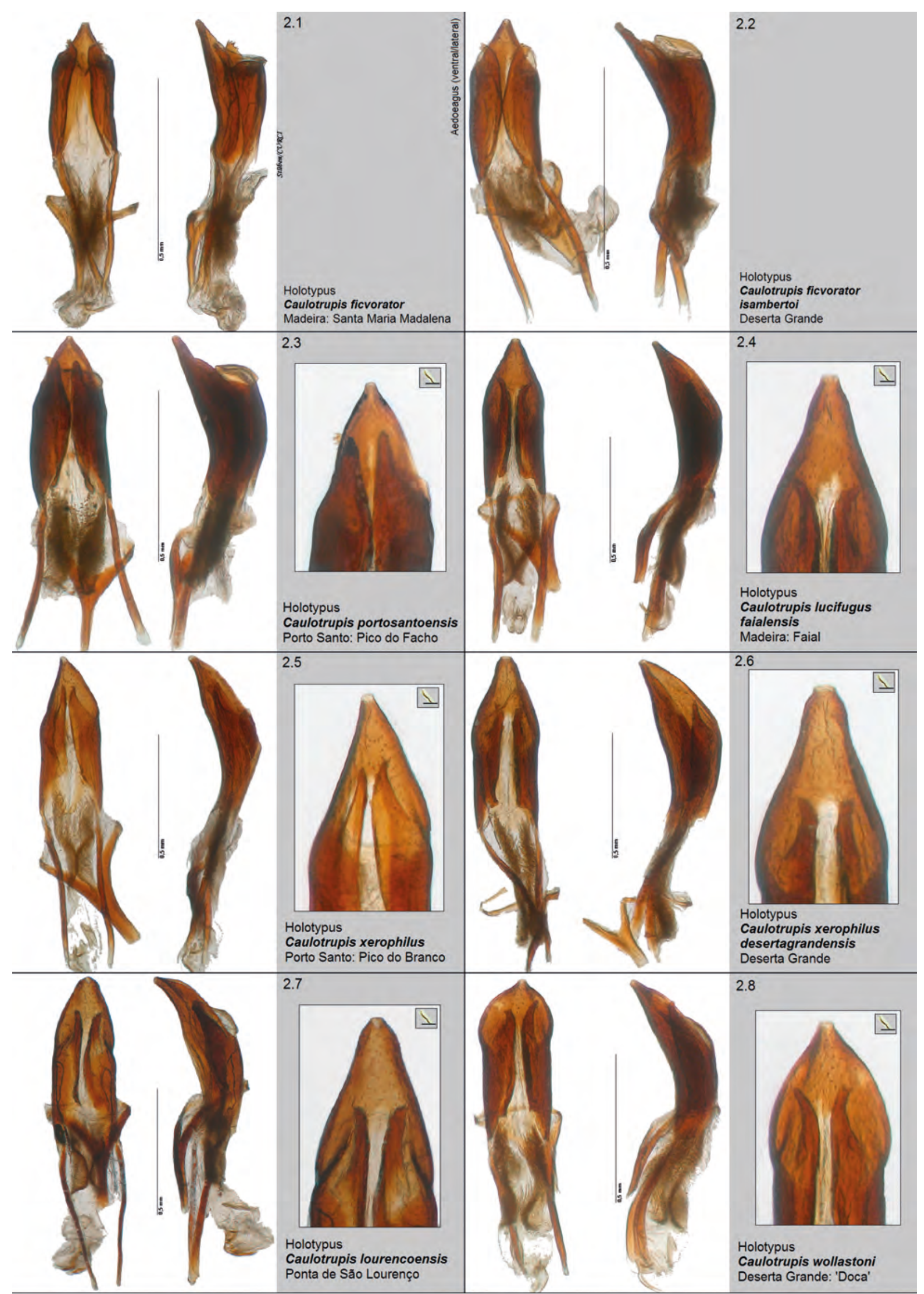

Fig. 2.1-2.8: Die neuen Caulotrupis-Arten. Aedoeagi (ventral / lateral); Apex (flach aufgelegt). 


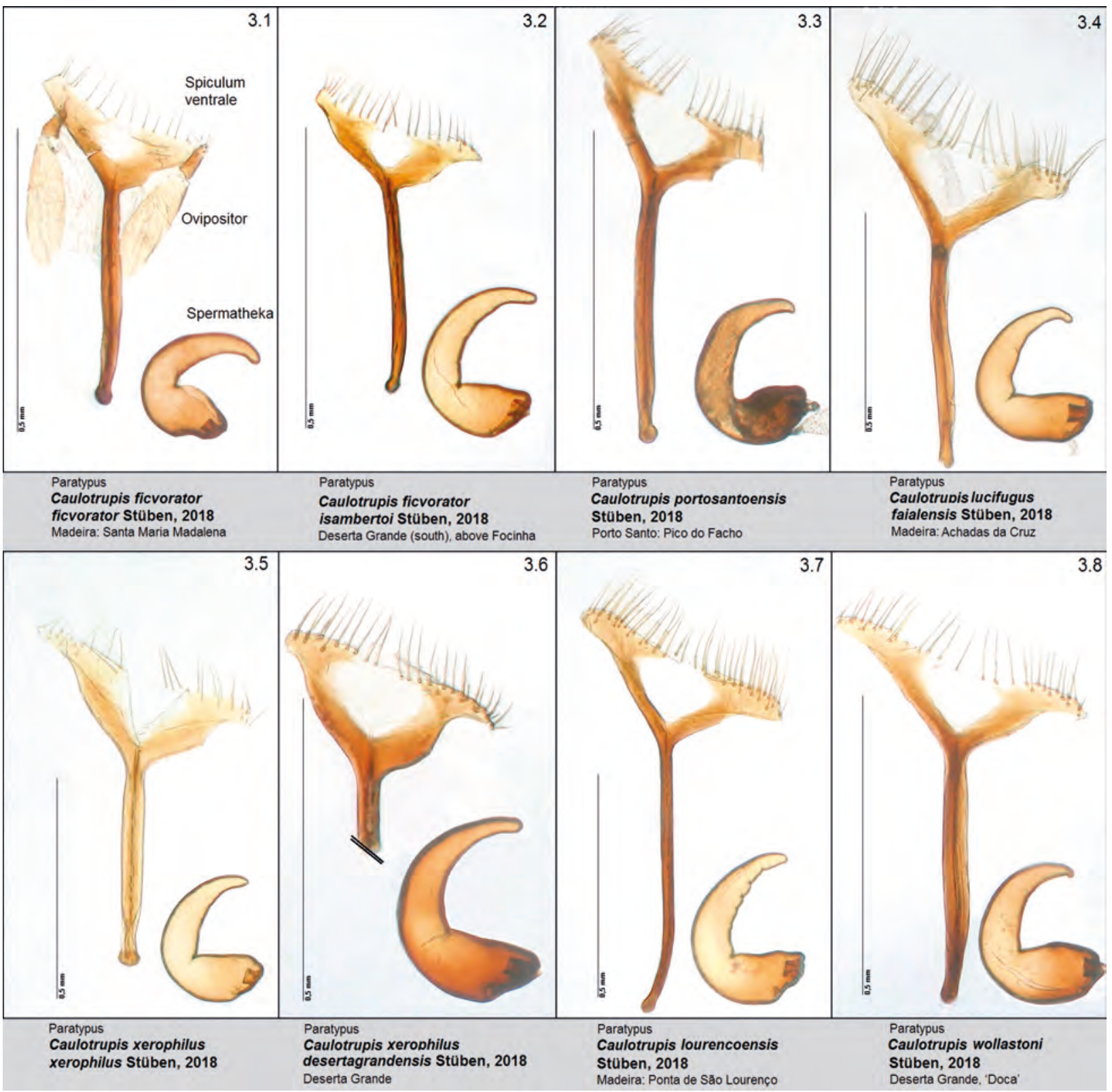

Fig. 3.1-3.8: Die neuen Caulotrupis-Arten. Weibliche Geschlechtsorgane - Spermatheka und Spiculum ventrale.

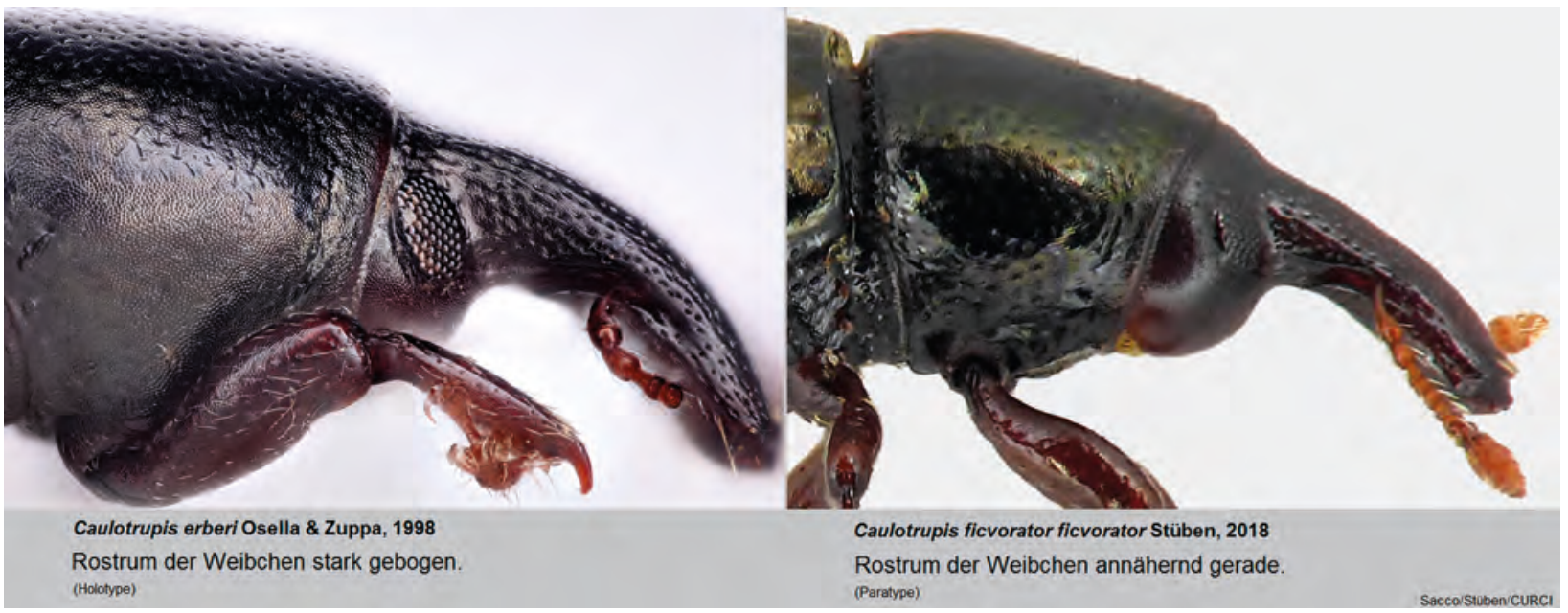

Fig. 5: Rostrum der Weibchen im Vergleich. 


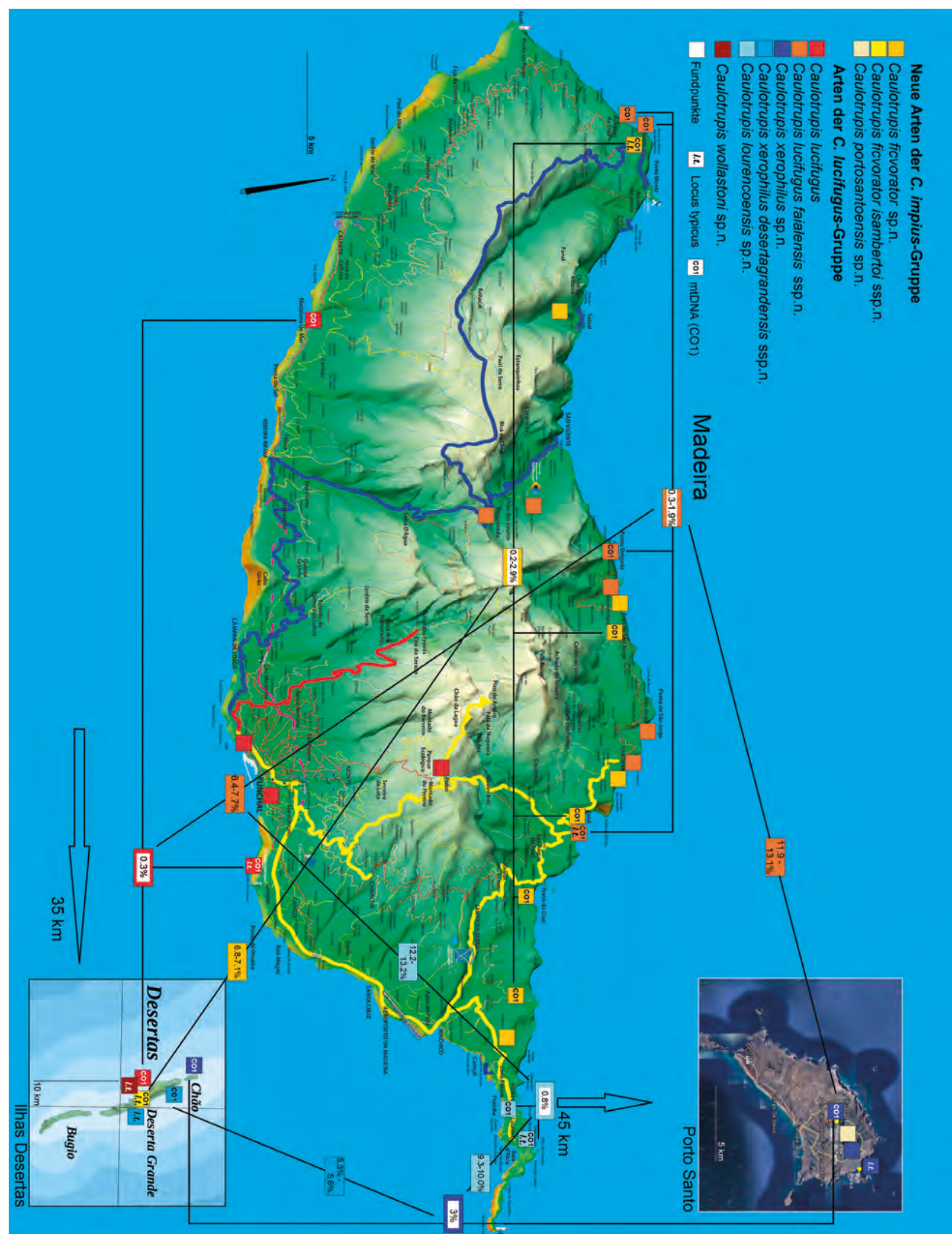

Fig. 4: Karte des Madeira-Archipels: Übersicht über die Verbreitung der acht neuen Caulotrupis-Arten und einer weiteren verwandten Art auf dem Madeira-Archipel unter Berücksichtigung der intra- $(<3 \%)$ und interartlichen Differenzen beim mitochondrialen CO1-Gen zwischen den Unterarten (> 6\%) und Arten (>9\%). (Zur umfassenden molekularen Anlayse und Systematik aller 17 makaronesischen Arten siehe demnächst: SтÜвEN \& SсHÜтte 2018). 